\title{
Dual Polarization Radar Observations of Thunderclouds in Winter Season
}

\author{
Yasuo SonOI ${ }^{1,5}$, Yasuyuki MAEKAWA ${ }^{2}$, Zen-Ichiro KAWASAKI ${ }^{3}$, Fumio Yoshino ${ }^{4}$, \\ and Shoichiro FUKAO ${ }^{5}$ \\ ${ }^{1}$ Technical Research Center. The Kansai Electric Power Company, Inc. Amagasaki, Hyogo 661, Japan \\ ${ }^{2}$ Department of Communication Engineering, Osaka Electro-Communication University, \\ Neyagawa, Osaka 572, Japan \\ ${ }^{3}$ Department of Electrical Engineering, Osaka University Suita, Osaka 565, Japan \\ ${ }^{4}$ Public Work Research Institute, Ministry of Construction Tsukuba, Ibaraki 305, Japan \\ ${ }^{5}$ Radio Atmospheric Science Center, Kyoto University Uji, Kyoto 611, Japan
}

(Received November 26, 1994; Revised July 18, 1995; Accepted August 29, 1995)

\begin{abstract}
The authors investigate the characteristics of thunderclouds associated with lightning phenomena in the winter season using the dual polarization Doppler radar of the Ministry of Construction known as the DND (Dobokuken-Nijuhenpa-Doppler) radar. This paper deals with the discrimination between different types of precipitation particles and presents the relationship between the movement of the particles and lightning processes. Our results suggest that the dual polarization observational mode, detecting both the horizontal radar reflectivity factor $\left(Z_{H}\right)$ and the differential reflectivity factor $\left(Z_{D R}\right)$, may discriminate between precipitation particles such as graupel or ice crystals, and that the observed radar echoes indicate a close relationship between the contact of these precipitation particles and the lightning process. Also, simultaneous field-mill observations suggest that graupel has negative charge while ice crystals have positive charge in thunderclouds. This electrical phenomenon is well described in terms of recent thunderstorm electrification theories at temperatures below $-10^{\circ} \mathrm{C}$.
\end{abstract}

\section{Introduction}

Lightning in the winter season along the coast of the Sea of Japan sometimes causes outage damage to electrical power transmission lines. Outage of the trunk ultra high voltage transmission lines is an especially large problem for electrical power supply. Therefore, a number of organizations, such as universities, Central Research Institute of Electric Power Industry (CRIEPI), and electric power companies have been investigating the winter season lightning phenomenon in its various aspects (e.g., Takeuti et al., 1978; Brook et al., 1982; Miyake et al., 1990). Some radar studies of lightning discharges from winter season thunderclouds have been reported. Recent radar observations have revealed the relationship between the occurrence of lightning and the temperature of the $30 \mathrm{dBZ}$ reflectivity height, and that the first lightning discharge was observed about 5 minutes after the $30 \mathrm{dBZ}$ reflectivity echo exceeded the $-20^{\circ} \mathrm{C}$ temperature level (Michimoto, 1991). On the other hand, some theoretical studies proposed riming-induced electric charge separation for producing lightning discharge, and insist that the charge polarities of ice crystals and graupel should be positive and negative, respectively, below $-10^{\circ} \mathrm{C}$ (Takahashi, 1978, 1984). Also, in relation to the vertical structure of winter season thunderclouds, peculiar characteristics of the clouds have been suggested (Kitagawa et al., 1994); that is, graupel particles are once densely formed in a cloud, but they do not stay stationarily but fall off rapidly, and the duration of dipole or tripole structures is very short and the positive monopole predominates in the whole life cycle of a cloud system. As a result, this gives rise to a lot of positive lightning discharges, which occasionally produces superbolts.

The winter-time thunderclouds thus show peculiar characteristics in the height distribution 
of ice particles and in their electric charge separation, and also in the mechanism for producing lightning discharges, which is not so clearly understood as that for summer-time thunderclouds. Therefore, it is very important to detect the kinds and distribution of ice particles in winter-time thunderclouds. Also the polarity of the electric charge carried by each kind of ice particle seems to be crucial to the lightning mechanism. In this sense, the dual polarization technique (Seliga and Bringi, 1976), which can estimate the overall shape of precipitating ice particles combined with electric field strength measurements on the ground, is a potential tool to investigate wintertime thunderclouds. Furthermore, our previous studies using the DND (Dobokuken-NijuhenpaDoppler) radar suggested that the lightning strokes are related to the ice particles, such as graupel and ice crystals, at a height of around 2-3 km (Fukao et al., 1991). The possibility of electric charge separation between these ice particles has also been presented (Maekawa et al., 1992).

In this study, the horizontal and vertical structure of winter-time thunderclonds observed by the DND radar is investigated in more detail using CAPPI (Constant Altitude Plan Position Indicator) analyses. Specifically, the relationship between precipitation particle distributions and lightning is examined using the dual polarization mode of the DND radar. This observation is the first attempt of its kind in Japan. We further discuss this relationship in terms of electric charge separation of the precipitation particles with the aid of field-mill measurements on the ground.

\section{Observation Method}

\subsection{Principle of the dual polarization radar observations}

The principle used in dual polarization radar observations of various precipitation particles is based on the different characteristics of radar echoes from targets when using horizontally and vertically polarized radio waves. This type of radar transmits radiowaves with horizontal and vertical polarizations alternately, receives each reflected wave and calculates radar reflectivity $z_{H}, z_{V}\left(Z_{H}, Z_{V}\right.$ in a logarithmic scale), and derives the differential reflectivity factor between them in $\mathrm{dB}$ as $Z_{D R}=10 \log \left(z_{H} / z_{V}\right)=Z_{H}-Z_{V}$. Using these factors, the dual polarization radar can discriminate between different types of precipitation particles, such as raindrops, ice crystals and graupel. Hall et al. (1984) proposed classification of precipitation particles using $Z_{D R}$ and $Z_{H}$. According to their study, precipitation particles with extremely small $Z_{D R}$ (nearly zero) and comparatively large $Z_{H}$ may correspond to graupel or hail, while those with extremely large $Z_{D R}$ (1.5-2.0 dB or more) and comparatively small $Z_{H}$ may correspond to ice crystals or snow flakes.

\subsection{Specifications of the DND radar}

The DND radar has a center-fed parabola antenna $2 \mathrm{~m}$ in diameter. Its operational frequency is $5280 \mathrm{MHz}$, and the peak output power of the transmitter is $75 \mathrm{~kW}$. The antenna gain is 36.6 $\mathrm{dB}$, and the beam width is $1.8^{\circ}$ for both horizontal and vertical polarizations. The sidelobes levels are suppressed by at least $23.6 \mathrm{~dB}$. The minimum detectable signal power of the low noise amplifier (LNA) is $-107.5 \mathrm{dBm}$. The pulse repetition frequency is $280 \mathrm{~Hz}$, and the pulse width is $2 \mu \mathrm{s}$. The range sampling interval is $500 \mathrm{~m}$, while the maximum range is $40 \mathrm{~km}$. The received signals are first amplified by the LNA and then converted to $30 \mathrm{MHz}$ IF signals. The IF signals are again amplified by a logarithmic amplifier, and the resulting video signals are converted to 10 bit digital data. Table 1 summarizes the specifications of the DND radar. Figure 1 shows a picture of the DND radar. Detailed descriptions of the instrumentation and observational techniques are given by Yoshino et al. (1989) and Fukao et al. (1991).

\subsection{CAPPI and distance-height cross section observations}

The PPI scan mode is operated at four elevation angles, $3^{\circ}, 5^{\circ}, 7^{\circ}$, and $9^{\circ}$. These elevation angles are rotated every $1 \mathrm{~min}$ in this order, and the antenna is scanned azimuthally 6 times $(6 \mathrm{rpm})$ at each elevation angle. This azimuth scan consists of 256 sweeps, and 80 range gates are 
Table 1. Specification of DND radar.

\begin{tabular}{|lc|}
\hline Maximum range & $40 \mathrm{~km}$ \\
Antenna & $2 \mathrm{~m} \phi$ parabola \\
Polarization & Horizontal/Vertical \\
Elevation & $0-90^{\circ}$ \\
Azimuth & $0-360^{\circ}$ \\
PPI Scan & $6 \mathrm{rpm}$ \\
Radio frequency & $5280 \mathrm{kHz} \quad(\lambda=5.68 \mathrm{~cm})$ \\
Peak power & $75 \mathrm{~km}$ \\
Pulse width & $2 \mu \mathrm{s}$ \\
Pulse repetition frequency & $280 \mathrm{~Hz}$ \\
Minimum detectable power & $-107.5 \mathrm{dBm}$ \\
Range resolution & $500 \mathrm{~m}$ \\
\hline
\end{tabular}

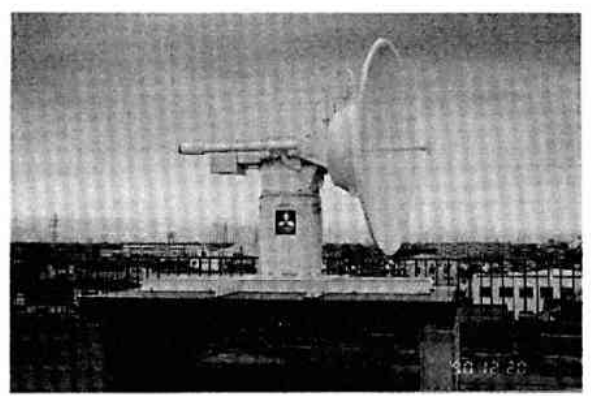

Fig. 1. The DND radar.

sampled in each sweep. In view of these system parameters combined with the aforementioned pulse repetition frequency, the number of samples of $Z_{H}$ and $Z_{V}$ used to derive $Z_{D R}$ is kept above at least 20 for each range bin, indicating an error in $Z_{D R}$ estimation of around $1 \mathrm{~dB}$ for the logarithmic amplifier (Bringi et al., 1983). For the PPI displays, these range and azimuth data are rearranged on a $1 \mathrm{~km} \times 1 \mathrm{~km}$ north-south/east-west grid for each elevation angle. In the present analysis, these gridded PPI displays for the four elevation angles are further arranged and averaged over the height range of $1.5-2.5 \mathrm{~km}$ to depict the so-called CAPPI displays. Thus the CAPPI displays are obtained from the four elevation angles about every $5 \mathrm{~min}$, which includes data processing and acquisition time. We can additionally depict distance-height cross sections of the thunderclouds in the east-west direction across the lightning location using PPI observations at the four elevation angles.

\section{Observational Results}

\subsection{Horizontal structure of thunderclouds}

The observations were carried out at the Sakata Construction Office $\left(38^{\circ} 55^{\prime} 32^{\prime \prime} \mathrm{N}\right.$, $\left.139^{\circ} 51^{\prime} 47^{\prime \prime} \mathrm{E}\right)$ in Sakata city, Yamagata prefecture, as shown on the map in Fig. 2. Thunder- 


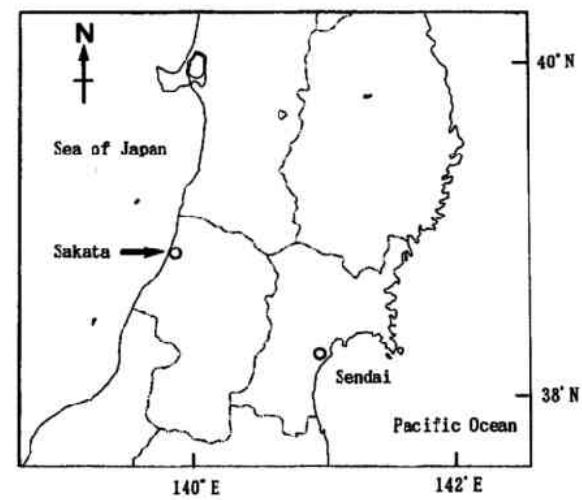

Fig. 2. Location of the observations.

Table 2. Time and location of lightning strokes on January 12, 1990.

\begin{tabular}{|c|c|c|c|}
\hline Stroke & Time & \multicolumn{2}{|c|}{ Location } \\
\hline A & $18: 37: 06$ & $39^{\circ} 04^{\prime} 35^{\prime \prime} \mathrm{N}$ & $139^{\circ} 42^{\prime} 41^{\prime \prime} \mathrm{E}$ \\
\hline B & $18: 43: 17$ & $38^{\circ} 56^{\prime} 14^{\prime \prime} \mathrm{N}$ & $139^{\circ} 39^{\prime} 42^{\prime \prime} \mathrm{E}$ \\
\hline C & $19: 09: 52$ & $38^{\circ} 52^{\prime} 03^{\prime \prime} \mathrm{N}$ & $139^{\circ} 42^{\prime} 50^{\prime \prime} \mathrm{E}$ \\
\hline
\end{tabular}

clouds were detected from 1816 to 1917 LT (LT $=9$ hours + UTC) on January 12, 1990. During this period, three cloud to ground (CG) lightning strokes were recorded within the radar coverage area by the LLP (Lightning Location and Protection) system near Sakata city. The time and location of these lightning strokes are shown in Table 2. We observed the thunderclouds by the DND radar using the PPI scan mode described above.

Figure 3 shows contour diagrams of 12 successive CAPPI displays for the horizontal radar reflectivity factor $\left(Z_{H}\right)$. These diagrams indicate the region mainly north and west of the radar coverage, and the contour lines are drawn at $10 \mathrm{dBZ}$ intervals. We can see that the thunderclouds form a band structure which moves from west to east as the cold front passes. In Fig. 3, crosses ( $\times$ ) and circles (o) denote extremely high and low $Z_{D R}$ values, respectively. That is, the crosses show radar echoes with $Z_{D R}$ larger than $1.5 \mathrm{~dB}$, corresponding to precipitation particles such as small ice crystals or snowflakes with comparatively flat shapes (Hall et al., 1984). On the other hand, the circles indicate radar echoes with small $Z_{D R}\left(-0.4 \leq Z_{D R} \leq 0.4 \mathrm{~dB}\right)$ and $Z_{H}$ larger than $30 \mathrm{dBZ}$, suggesting round and/or rotating ice particles such as graupel (Aydin and Seliga, 1984). In addition, the high $Z_{D R}$ values $(\times)$ consistently appear near clouds where $Z_{H} \simeq 20 \mathrm{dBZ}$, even though we do not put any restriction on the echo power $\left(Z_{H}\right)$ itself in extracting this type of echo $(x)$ in Fig. 3. Therefore, the predominance of high $Z_{D R}$ values above the severe criterion is considered to reflect a real physical phenomenon such as enhancement of small ice crystals with flat shape (Maekawa et al., 1993).

The first (A), second (B) and third (C) lightning strokes fall on panels $\sharp 5,6$ and 12 of Fig. 3 . The location of each lightning stroke (A, B and C) is marked by a large asterisk. As shown in these panels, each asterisk is seen near a cloud with strong echoes, and the graupel echoes (o) can be seen around the center of the thunderclouds at the moment of the lightning strokes. 

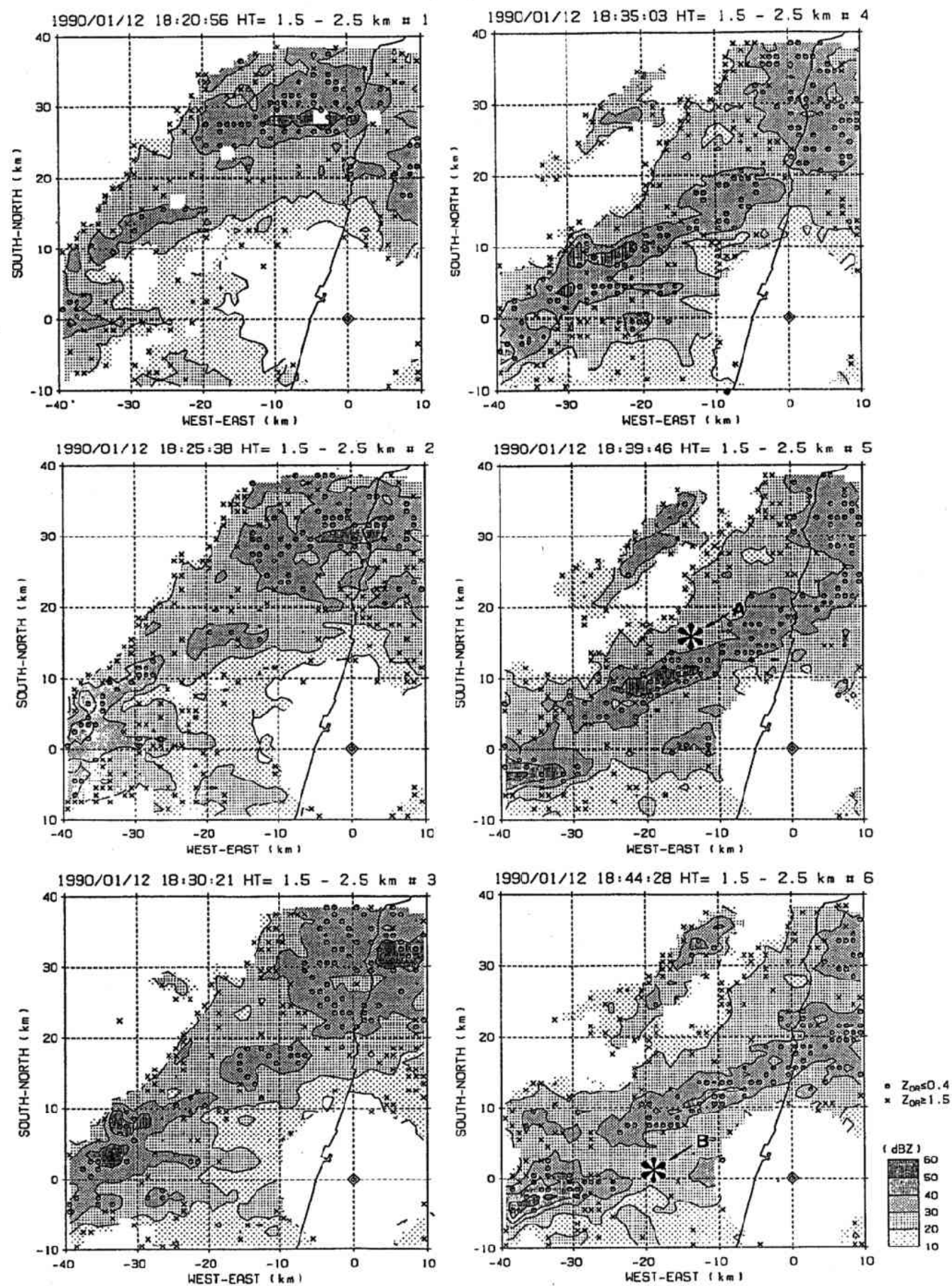

Fig. 3. CAPPI displays of thundercloud observations at the height of $1.5-2.5 \mathrm{~km}$. The thick line indicates the coast line and to the left of the line is the Sea of Japan. A large asterisk indicates the lightning location (A, $B$, and $C$ ) in panels $\sharp 5, \sharp 6$ and $\sharp 12$. 

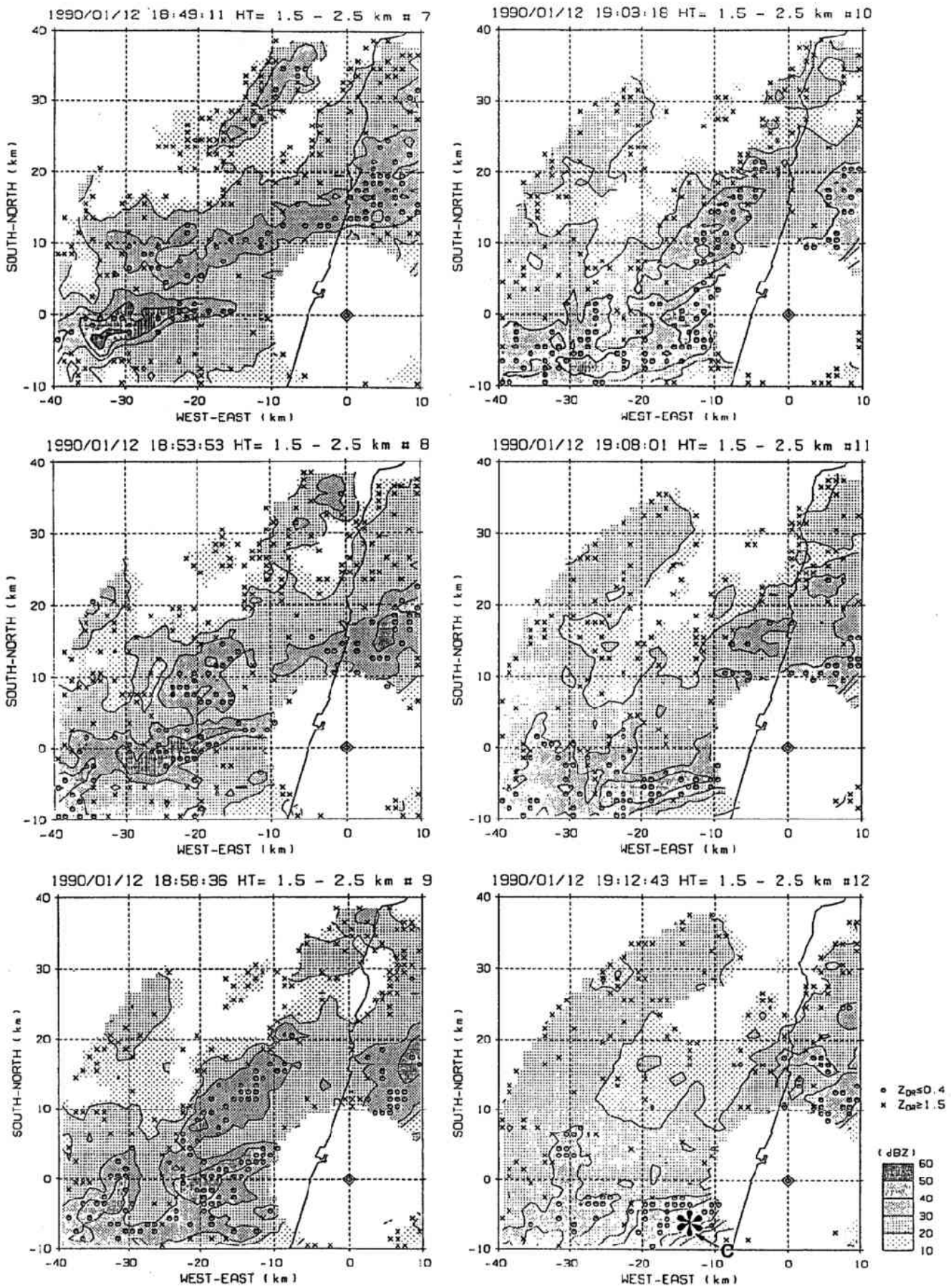

Fig. 3. (continued). 

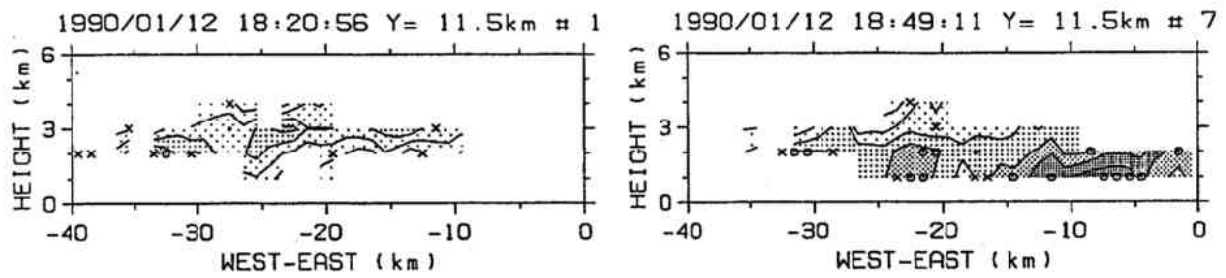

$1990 / 01 / 12 \quad 18: 25: 38 \mathrm{Y}=11.5 \mathrm{~km}$ \# 2
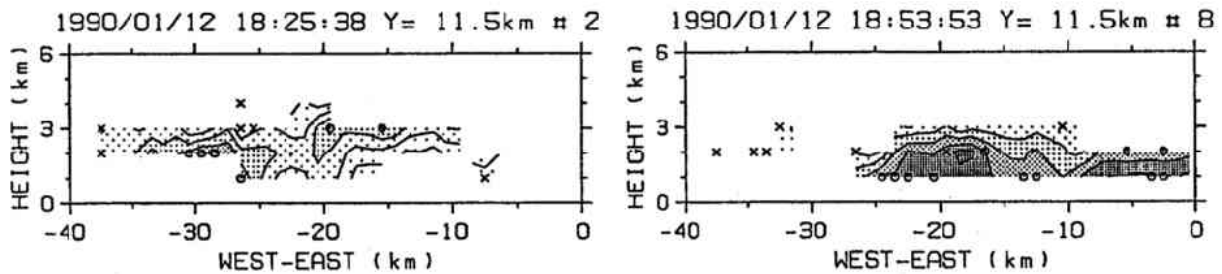

$1990 / 01 / 1218: 30: 21 \mathrm{Y}=11.5 \mathrm{~km}$ a 3

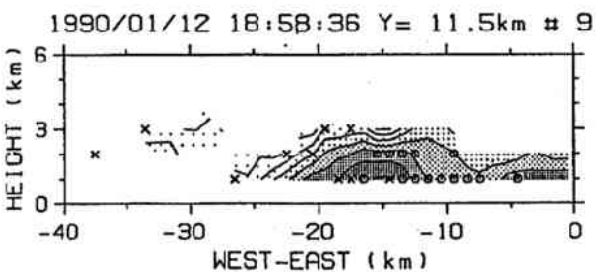

WEST-EAST $(\mathrm{km})$
$1990 / 01 / 12 \quad 18: 35: 03 \quad Y=11.5 \mathrm{~km}=4$
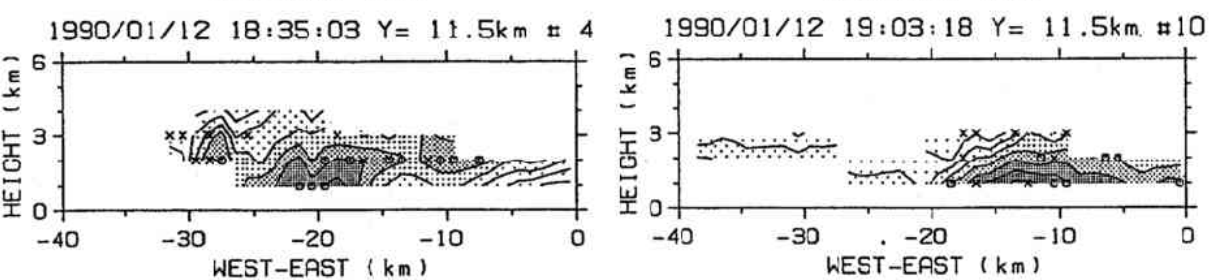

$1990 / 01 / 12 \quad 18: 39: 46 \quad Y=11.5 \mathrm{~km}$ म 5

$1990 / 01 / 1219: 08: 01 \quad Y=11.5 \mathrm{~km}$ म 11
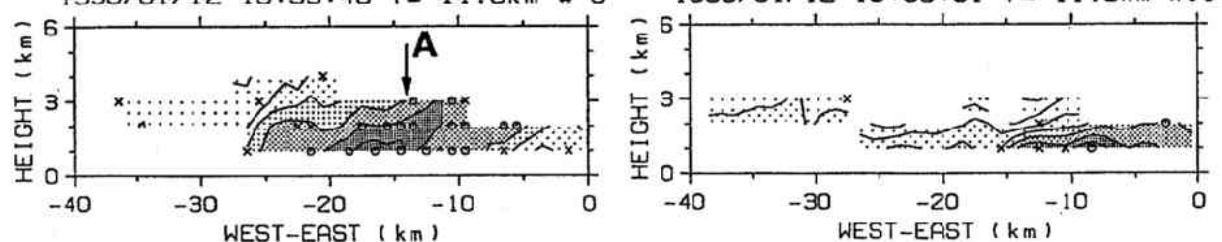

- $\mathrm{Z}_{\mathrm{OR}} \leq 0.4$

WEST-EAST $(\mathrm{km})$

$1990 / 01 / 1219: 12: 43 \quad Y=11.5 \mathrm{~km}$ \# 12

$1990 / 01 / 12 \quad 18: 44: 28 \quad Y=11.5 \mathrm{~km}$ \# 6

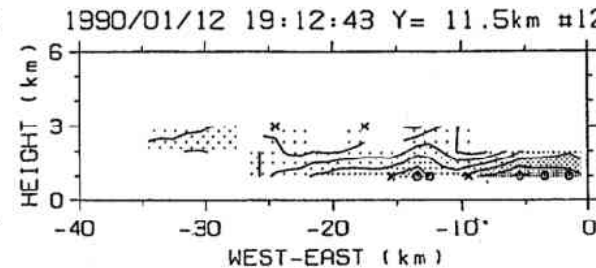

$(\mathrm{dBZ})$
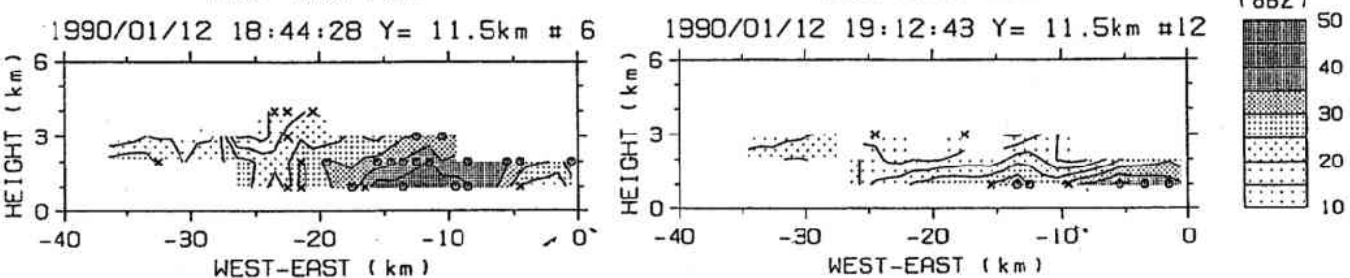

Fig. 4. Distance-Height sections of thunderclouds producing the first lightning stroke (A: arrow). 


\subsection{Vertical structure of thunderclouds}

Next, distance-height sections of the thunderclouds which produced the first lightning (A) are shown in Fig. 4. In the panel $\sharp 1$, no graupel echoes (o) can yet be seen above $3 \mathrm{~km}$ height, though small ice crystals $(\times)$ can been seen. In panels $\sharp 2-3$, however, graupel echoes begin to appear around $3 \mathrm{~km}$ height as the thunderclouds approach 10-20 km distance from the radar site. Furthermore, graupel echoes increase and precipitate in panels $\sharp 4-5$, and are then mixed with small ice crystals. Note that the instant of panel $\sharp 5$ agrees with the lightning stroke very well in time and location, as shown by the vertical arrow. At this time, the temperature at $3 \mathrm{~km}$ altitude was probably lower than $-10^{\circ} \mathrm{C}$, as inferred from the ground temperature of $5-8^{\circ} \mathrm{C}$ at the radar site, as well as from aerological data at Akita and Wajima. After the lightning stroke, the thundercloud structure is maintained for about ten minutes, as seen from panels $\sharp 6$ to 9 . However,as it approaches within $5 \mathrm{~km}$ of the coast, the thundercloud dissipates gradually, as seen in panels $\sharp 11-12$. These features are similar to those observed during other lightning strokes.

\section{Charge Separation of the Precipitation Particles}

An advantage of subsequent thundercloud observations is that a field-mill electric field sensor was placed at the radar site after January 16, 1990, to estimate electrification of the clouds approaching the site. Note that if a thundercloud is comparatively isolated from other clouds in time and space, and passes just near or over the radar site, we can roughly infer the polarity of each kind of ice particle, such as graupel or ice crystals, as indicated by the dual polarization radar observation.

On January 18, 1990, another thunderstorm event was observed with the antenna beam fixed at $26^{\circ}$ elevation and $262^{\circ}$ azimuth. Figure 5 shows (a) the detected precipitation particles of the thundercloud and (b) the electric field strength measured by the field-mill sensor. The vertical scale of Fig. 5(a) indicates the slant range from the radar site as well as the height. A lightning discharge from this thundercloud was recorded at $1908 \mathrm{LT}$, just before the fixed-beam observations. Moreover, the thundercloud had been shown to be a fairly isolated one and directly approaching the radar site by preceding Doppler observations. As Figs. 3 and 4, crosses $(x)$ or pluses $(+)$ denote precipitation particles such as small ice crystals or snowflakes, and circles (o) denote round and/or rotating ice particles such as graupel, except that smaller circles after 2005 LT indicate low $Z_{D R}$ data points with $Z_{H}$ less than $30 \mathrm{dBZ}$.

In Fig. 5, we can see the tendency for the electric field to be negative when graupel (o) appears around the cloud base at about $2 \mathrm{~km}$ height and falls down to the radar site. On the other hand, the electric field tends to be positive when ice crystals or snowflakes $(x)$ appear around the cloud top at about $4 \mathrm{~km}$ height and are floating over the radar site. Note that such dispositions of negative and positive charges accumulated at the cloud base and top, respectively, are generally found in cumulus-type clouds, and a number of field-mill observations have already shown this kind of distribution (e.g., Reiter, 1992). Also, these height distributions may be explained by features of the recent riming electrification theories (Takahashi, 1978, 1984) above and below the $-10^{\circ} \mathrm{C}$ height. Namely, according to his experiments, the electric charge in thunderclouds develops from the contact of ice crystals and graupel, and the magnitude and polarity of the electrification depend on the temperature and cloud water content. Also, the experimental results indicate that graupel has negative charge for temperatures of -15 to $-10^{\circ} \mathrm{C}$ and cloud water content of 0.4 to $1.0 \mathrm{~g} / \mathrm{m}^{3}$. When ice crystals collide with graupel, the free protons/negative dislocation pair is formed on the graupel surface, and the protons move toward ice crystals because of the warmer temperature of graupel. As a result, graupel is electrified negatively while ice crystals are electrified positively.

On the other hand, the observational results of cloud water content in convective snow clouds over the Sea of Japan using hydrometeor video dropsondes were reported by Murakami et 

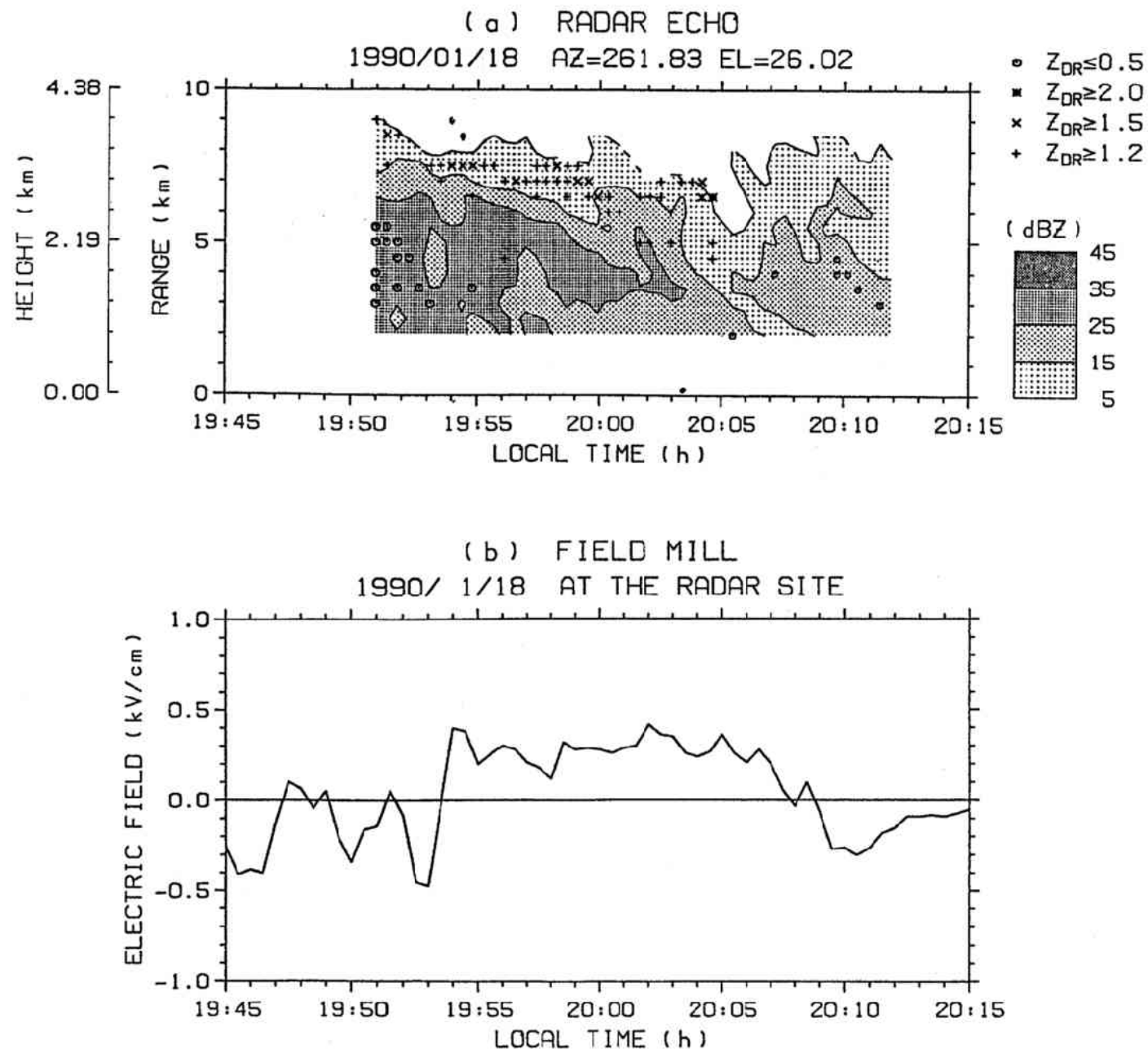

Fig. 5. (a) Time-height section of precipitation particles approaching to the radar site and (b) electric fields simultaneously measured by a field-mill, on January 18,1990 .

al. (1994). Fortunately, that observation was carried out around Tobishima Island, near Sakata city, although the observational time period was different. Those sondes were launched in Feb. 1991, and denoted that cloud water content in the snow clouds was 0.4 to $0.7 \mathrm{~g} / \mathrm{m}^{3}$ at the height above the $-10^{\circ} \mathrm{C}$ level. The $-10^{\circ} \mathrm{C}$ level of the radar observation (about $3 \mathrm{~km}$ ) was higher than that of the sonde observation (about $1.5 \mathrm{~km}$ ). Therefore, in the thunderclouds we observed, the convection was more developed and cloud water content was more abundant, and so the riming electrification and electrical charge accumulation functioned more strongly, resulting in lightning discharges. Our observations showed that graupel fell down after lightning discharges, because it is much heavier than ice crystals or snowflakes, and so negatively charged graupel made the electric field negative, while positively charged ice crystals or snowflakes floated over the radar site and made the electric field positive in Fig. 5. These observations can be explained the riming electrification theory.

In addition, similar observational results (shown in Fig. 6) were obtained with the antenna 

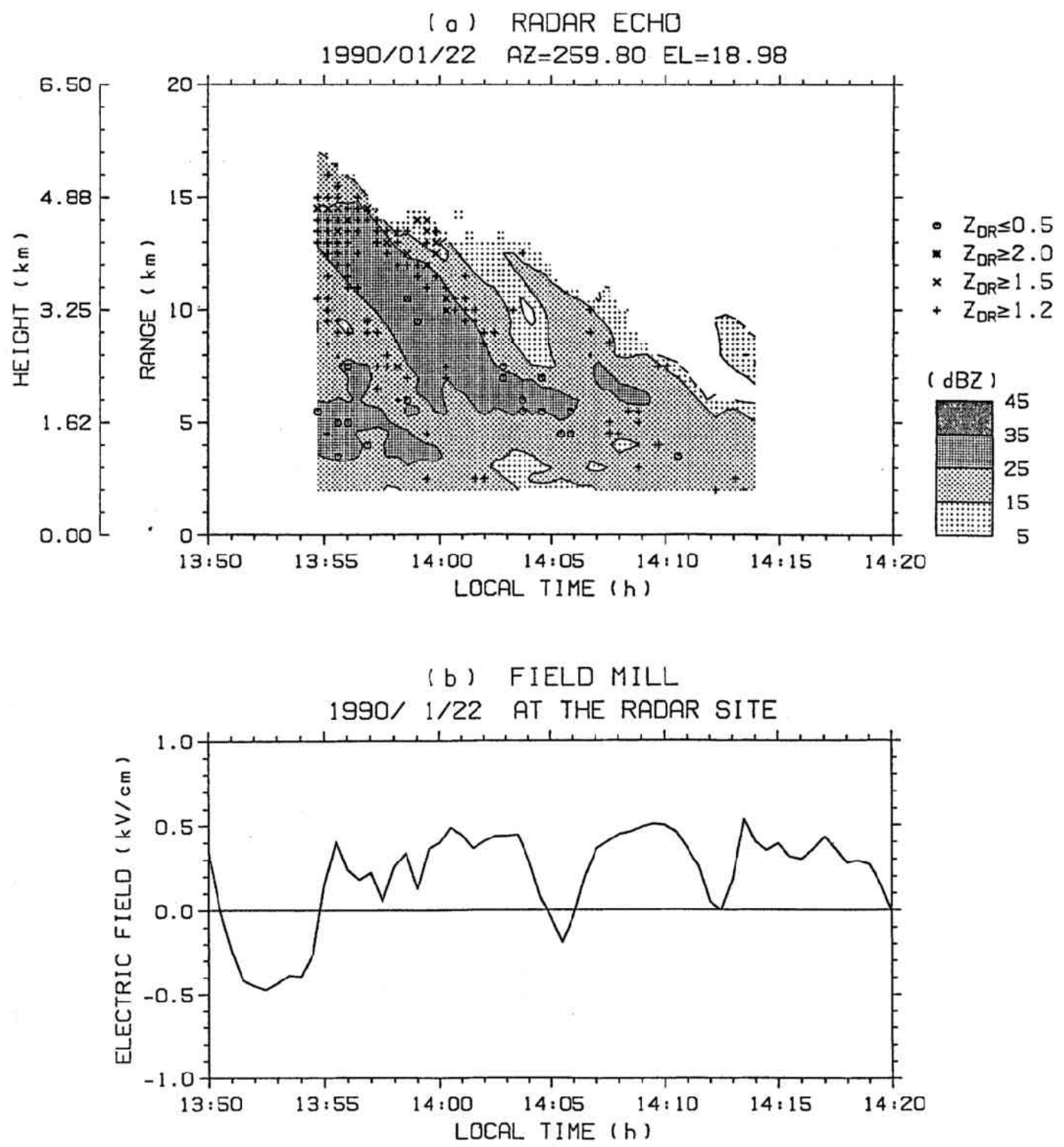

Fig. 6. (a) Time-height section of precipitation particles approaching to the radar site and (b) electric fields simultaneously measured by a field-mill, on January 22,1990 .

beam fixed at $19^{\circ}$ elevation and $260^{\circ}$ azimuth, on January 22,1990 , although no lightning discharge was observed on this day. In Fig. 6 (a) and (b), we can see the same tendency as shown in Fig. 5, that the electric field is negative when graupel (o) approaches the radar site and is positive when ice crystals or snowflakes $(x)$ approach the radar site. Also in this observational period, the temperature at heights above $2 \mathrm{~km}$ is estimated to have been lower than $-10^{\circ} \mathrm{C}$. Therefore, the mechanism of riming-induced electric charge separation is also suggested to have functioned in this event, although lightning discharges were not actually induced. Note that in Fig. 6 ice 
crystals or snowflakes were found at heights much lower than in Fig. 5. This suggests that the updraft in that cloud was weaker and not strong enough to produce lightning, though the riming electrification mechanism functioned.

\section{Conclusion}

This study has presented dual polarization radar observations of winter-time thunderclouds that occurred along the coast of the Sea of Japan. The dual polarization radar enables us to discriminate between types of precipitation particles using the horizontal radar reflectivity factor $\left(Z_{H}\right)$ and the differential reflectivity $\left(Z_{D R}\right)$. Namely, ice crystals or snowflakes appear with $Z_{D R}$ larger than $1.5 \mathrm{~dB}$, and graupel appears with small $Z_{D R}\left(-0.4 \leq Z_{D R} \leq 0.4 \mathrm{~dB}\right)$ with $Z_{H}$ larger than $30 \mathrm{dBZ}$. Also, we noted that there is a close relationship between the contact of ice crystals and graupel and lightning at heights where the temperature is below $-10^{\circ} \mathrm{C}$, and that simultaneous field-mill observations show that the ice crystals or snowflakes are charged positively, whereas graupel is charged negatively. These phenomena qualitatively coincide with features of recent thunderstorm electrification theories for temperatures below $-10^{\circ} \mathrm{C}$. Thus, observations using the dual polarization radar are important to advance our knowledge of lightning physics, and in the future this type of radar technique should play an important role in obtaining realistic physical parameters for the prediction of lightning.

The authors thank Prof. T. Takahashi for helpful and constructive comments. The contributions of Mr. H Mizuno and Mr. T. Ikawa of the Public Work Research Institute, Ministry of Construction during this experiment are gratefully acknowledged. The LLP system data were supplied by the courtesy of the Tohoku Electric Power Company.

The Editor thanks H. Ueda and another referee for their assistace in evaluating this paper.

\section{REFERENCES}

Aydin, K. and T. A. Seliga, Radar polarimetric backscattering properties of conical graupel, J. Atmos. Sci., 41, 1887-1892, 1984.

Bringi, V. N., T. A. Seliga, and S. M. Cherry, Statistical properties of the dual-polarization differential reflectivity $\left(Z_{D R}\right)$ radar signal, IEEE Trans. Geosci. Remote Sens., GE-21(2), 215-220, 1983.

Brook, M., M. Nakano, and P. Krehbiel, The electrical structure of the Hokuriku winter thunderstorms, J. Geophys. Res., 87, 1207-1215, 1982.

Fukao, S., Y. Maekawa, Y. Sonoi, and F. Yoshino, Dual polarization radar observation of thunderclouds on the coast of the Sea of Japan in the winter season, Geophys. Res. Lett., 18, 179-182, 1991.

Hall, M. P. M., J. W. F. Goddard, and S. M. Cherry, Identification of hydrometeors and other targets by dualpolarization radar, Radio Sci., 18, 132-140, 1984.

Kitagawa, N. and K. Michimoto, Meteorological and electrical aspects of winter thunderclouds, J. Geophys. Res., 99, 10,713-10,721, 1994.

Maekawa, Y., S. Fukao, Y. Sonoi, and F. Yoshino, Dual polarization radar observations of anomalous winter-time thunderclouds in Japan, IEEE Trans. Geosci. Remote Sens., GE 30(4), 838-844, 1992.

Maekawa, Y., S. Fukao, Y. Sonoi, and F. Yoshino, Distribution of ice particles in winter-time thunderclouds detected by a $\mathrm{C}$ band dual polarization radar: A case study, J. Geophys. Res., 98, 16,613-16,622, 1993.

Michimoto, K., A study of radar echoes and their relation to lightning discharge of thunderclouds in the Hokuriku district Part I: Observation and analysis of thunderclouds in summer and winter, J. Meteor. Soc. of Japan, 69(3), 327-335, 1991.

Miyake, K., I. Kishizima, T. Suzuki, H. Mitani, and M. Takashima, Characteristics of winter lightning current in the coastal area of the sea of Japan, Trans. IEE of Japan, 110-B, 944-951, 1990.

Murakami, M., T. Matsıo, H. Mizuno, and Y. Yamada, Mesoscale and microscale structure of snow cloud over the Sea of Japan Part I: Evolution of microphysical structure in short-lived convective snow clouds, J. Meteor. Soc. of Japan, 72(5), 671-694, 1994.

Reiter, R., Phenomena in atmospheric and environmental electricity, 541pp, Elsevier, Amsterdam, Netherlands, 1992.

Seliga, T. A. and V. N. Bringi, Potential use of differential reflectivity measurements at orthogonal polarization for measuring precipitation, J. Appl. Meteorol., 15, 69-76, 1976. 
Takahashi. T., Riming electrification as a charge generation mechanism in thunderstorms, J. Atmos. Sci., 35, 1,536-1,548, 1978.

Takahashi. T., Thunderstorm electrification-A numerical study, J. Atmos. Sci., 41, 2,541-2,558, 1984.

Takeuti, T., M. Nakano, M. Brook, D. J. Raymond, and P. Krehbiel, The anomalous winter thunderstorms of the Hokuriku Coast, J. Geophys. Res., 83, 2385-2394, 1978.

Yoshino, F., N. Ishii, H. Mizuno, and T. Ikawa, Quantitative precipitation measurement and identification of hydrometeors with dual linear polarization radar, Pacific International Seminar on Water Resources Systems, Tomamu, 1989. 